\title{
VISTA OF CLEFT LIP AND PALATE IN INDIA
}

Sumeet W. Ghonmode, Ashita R. Kalaskar, Ritesh R. Kalaskar, Revant Chole,

Priyanka Bhushan, Fareedi Mukram Ali

1. Lecturer, Department of Orthodontics, Government Dental College \& Hospital. Mumbai.

2. Lecturer, Department of Oral Diagnosis Medicine \& Radiology, VSPM Dental College \& Research Center, Nagpur, Maharashtra, India.

3. Associate Professor \& HOD, Department of Pedodontics, Government Dental College \& Hospital, Nagpur, Maharashtra, India.

4. Associate Professor, Department of Oral Diagnosis Medicine \& Radiology, Modem Dental College, Indore.

5. Senior Lecturer, Department of Public Health Dentistry, SMBT Dental College, Sangamner Taluka, Ahmednagar Dist.

6. Reader, Department of Oral \& Maxillofacial Surgery, SMBT Dental College, Sangamner Taluka, Ahmednagar Dist.

\section{CORRESPONDING AUTHOR}

Dr Fareedi Mukram Ali

Reader, Dept of Oral \& Maxillofacial Surgery.

SMBT Dental College, Sangamner Taluka, Ahmednagar Dist

E-mail: faridi17@rediffmail.com

Ph: 00919326325156.

ABSTRACT: Congenital craniofacial anomalies like orofacial clefts are of concern for the entire health organisation all over the world. World Health Organisation (WHO) has started its own surveys and is analysing the data available from various countries. WHO has standardised the process of collection of data and has provided a multidisciplinary approach for the treatment of such cases. Surveys, research and application of multidisciplinary treatment strategies are successful on the urban Indian population but a lot needs to be done in terms of rural areas of India (which constitutes $70 \%$ population of India) and is posing a serious challenge of overall objective of health for all.

KEYWORDS: Cleft lips \& Palate + Craniofacial anomalies

INTRODUCTION: Cleft of lip, hard and soft palate are the most common congenital abnormalities of the craniofacial structure. Worldwide incidence of cleft lip and palate is 1 in 600. (1) The overall worldwide prevalence of cleft lip with or without the cleft of palate is 9.92 per 10,000 . The prevalence of cleft lip is 3.28 per 10,000 , and that of the cleft lip and palate together is 6.64 per 10,000. (2) Lowest incidence occurs in Native American tribes of Montana, USA, which is $1: 2076 .{ }^{(3)}$

Indian sub-continent still remains one of the most populous areas of the world with an estimated population of 1.1 billion in India alone. The Approx birth rate is estimated to be 24.5 million births per year and prevalence of clefts cases are somewhere between 27,000 and 33,000 cases per year. Inequalities exist, both in access to and qualities of cleft care with distinct differences among urban versus rural areas. Due to this inequality along with lack of awareness had lead to the accumulation of untreated clefts of the lip and palate leading to a significant health care problem in India.

The term cleft lip and palate inadequately describes the potential complexities of the deformity which may involve nose, lips, alveolus or palate. As a consequence breathing, appearance, dentition, dental occlusion facial growth, speech and hearing can all be affected 
leading to psychosocial implications.(4) It may not be the end of life but for children suffering from cleft problem, it goes beyond the obvious disfigurement of face to repeated infections, social stigma, and mental impairment that affects the speech, hearing, and dentition development or dentition as a whole. Such children are often misbehaved about their cleftrelated problems such as speech, teeth and lip appearance etc which results in lower level of confidence among such children.(5) Research has shown that normal children are considered to be brighter having more positive social behaviour, socially more accepted then those children suffering from cleft diseases. These children suffer with emotional "burn out" in adolescence. Therefore, it has been suggested that these patients should also be included in national policies for integration of handicapped people, in agreement with programs of human rights, establishing a collaborative action between state and society. This would assure their inclusion in the socioeconomic and cultural context and equal opportunities in society, without privileges or paternalism. ${ }^{(6)}$

Studies have shown association of clefts disease with haematological abnormalities such as anemia, eosinophilia and defects of the clotting mechanism. (7) A common clinical observation among children with cleft palate is high prevalence of recurrent upper and lower respiratory tract infection. ${ }^{(8)(9)}$

Indian sub continent being a geographically and economically different region than others, the demographic, prenatal and clinical profile of the clefts cases found in this region also differs. The condition in tropical countries like India becomes even worse due to poverty and illiteracy. India being economically a developing country is expanding the medical facilities available in the rural area. The various geographically difficult regions such as mountainous region of North and North-eastern India and plains of the Central Indian and the Southern region have diverse culture, religion and living standards. Due to insufficient, ineffective and disproportionate penetration of health care facilities the population at large have suffered a lot in terms of basic health care facilities. However certain NGOs and government agencies by means of various health projects have done excellent work but still lot of rural masses are deprived of quality and good health care. In addition, due to lack of awareness and illiteracy rate, the patients of cleft remain untreated or misguided by some quacks. (10)

\section{DOCUMENTATION OF CRANIOFACIAL ANOMALIES AND CLEFT LIP AND PALATE IN INDIA}

India is one of the many countries of the world where documentation of birth anomalies is incomplete or not done. Efforts and hard work of certain NGOs and government health organisations has lead to an improvement in terms of health care needs, social and economical upliftment of Oro-facial Cleft (OFC) children but the problem is aggravated manifold due to un availability of reliable and complete record of cleft cases statistics because of want of proper infrastructure and also due to poor association and non sharing of data recorded by various agencies dealing with craniofacial anomalies in India. It is well known fact that in many parts of India the parents of a child born with a cleft have no access to counselling on the care and treatment modalities of the disease affecting their children. Cleft lip and palate may be perceived to be a life threatening abnormality by such parents and also there is less awareness of the fact that clefts cases can be surgically repaired with considerable success both aesthetically and functionally. The lack of knowledge and resources results in unacceptable delay in seeking and receiving adequate medical care of such cases, due to which, many infants suffering from OFC die of malnutrition or infection. This grim situation is further compounded by failure of healthcare authorities to recognize craniofacial anomalies as a notifiable disease.(4) 
From the facts presented above it becomes important that the issue of registering of cases of birth deformity is taken seriously in India. Various studies on cleft cases should be performed along with collection of data from different centres covering the various geographical and economical section of India, presence of consanguinity and high and low incidence areas as noted in previous studies. The agency entrusted with the task of registering of cases should establish network and communication with various neonatal units present in the different cities which are routinely involved in the collection of statistics of the newborns. In each center, a medical doctor and a social worker should work together for diagnosing and collection of appropriate information and data regarding birth anomilities.(2) They should also liase and collaborate with other medical centres within their area of work for collection of data. Craniofacial anomalies including cleft lip and palate would be a sub-set of the data collected, and the protocols used should be governed by the guidelines as issued by the WHO.(2)

MULTIDISCIPLINARY APPROACH AND STATUS OF SURVEYS IN INDIA: It is widely recognized that the optimum approach to the treatment of children born with cleft defects, either of the lip or palate, is a multidisciplinary approach as the treatment requires combined efforts from a paediatrician, orthodontist, specialist nurse, cleft surgeon, speech therapist and ear, nose and throat specialist (ENT) and because of which there is a need to felt provide the best possible collective expertise so as to ensure that correct and proper treatment interventions are carried out at the appropriate time to result in best possible functional and aesthetic result.(2)

Multidisciplinary treatment approach is the need for treatment of OFC children but such a scenario is best available in urban area while its application in rural area is still debatable due to lack of facilities available. Due to increased awareness Indian researchers have also started carrying out study and research on OFC children collecting data from various regions of the country. Various studies have shown that due to improvement of economic condition, literacy rate and more importantly the improvement in health care infrastructure are resulting in better care of cases suffering from cleft disease. Situation has also shown marked improvement due to the Involvement of the non-governmental organizations in providing quality health care to the general masses especially to the weaker sections of the society is rapidly changing the cleft care scenario in the country. But despite the general improvement of the environment there is lack of interdisciplinary treatment approach at majority of the centres, and hence there is a need for better and effective collaboration among the specialist for the health care needs of the cleft cases.(11) Consanguineous relationship and illiteracy rate among the rural masses has also resulted in a situation of increased developmental deformity as well as inefficiently handling of the cleft cases in India.(12)(13)

Many researches through their studies have revealed the genetic complexity in Indian children suffering from oral cleft lip and palate.(14,15,16,17,18) India being one the fastest developing country is bubbling with young and enthusiastic researchers who are struggling hard to find the genetic reasons along with the environmental effects resulting in oral clefting in Indian population. Surveys of rural and urban Indian population and statistical analysis and evaluation of the data are the main areas of concern, as these are also in developing state but are progressing positively with the help of the government health organisations together with certain NGOs and many researchers. 
ENVIRONMENTAL FACTORS:Epidemiological and experimental evidences suggests that environmental risk factors such as maternal exposure to tobacco, tobacco smoke, alcohol, poor nutrition, viral infection, improper medications, and teratogens at the workplace and home in early pregnancy are some of the important etiological factors. The role of maternal nutrition and, multivitamins in particular, in orofacial clefts cases remains unclear. Furthermore, assessments of dietary intake or biochemical measures of nutritional status of OFC cases are challenging and often not available among the many impoverished populations suffering from the highest rates of orofacial clefts disease. The main environmental factors which has been reported to possibly increasing the risk of orofacial clefts cases is tobacco smoking, (19) alcohol consumption,(20) solvents(21) and agricultural chemicals.(22) Certain types of anti-epileptic drugs have also been reported to increase the risk.(23) It is, however, an established fact that the magnitude of the risk of recurrence of orofacial clefts to siblings.(24)increases after two or more affected siblings and is greater than that predicted by the familial aggregation of environmental risk factors. If measure of genetic susceptibility are not taken into account in epidemiological studies, measures of the relative risk of a disease associated with an environmental factor can be diluted considerably.(25)

GENETIC FACTORS: There are two types of CL-P: syndromic and nonsyndromic. Nonsyndromic CL-P represents almost half of facial malformations and could be familial. Nonsyndromic cleft lip with or without cleft palate (CL-P) is one of the most frequently occurring congenital malformations among live births. This prevalence varies widely, depending on the ethnicity and geographic location of the population, ranging from 1 in 300 to 1 in 2,500(26) In the United States, it affects 1 in 700-1,000 newborns each year and is the fourth most common birth defect. In India, cleft lip/palate occurs in nearly 1 in 500 live births and the majority of these defects are not corrected either surgically or asymptomatically.(27)Although Asians have the highest rate of orofacial clefts (OFCs) at birth; majority of the genetic studies have been conducted on white population. OFC may be included as one of the manifestations in more than 400 recognised syndromes. Some of the common syndromes and/or anomalies associated with clefting include Apert,(28) Meckel,(29)Treacher Collins,(30) and van der Woude syndromes.(31) Dental anomalies such as supernumerary, hypoplastic, or congenitally missing teeth and malocclusion are common in patients affected with CL-P.

Orofacial clefts present as part of the phenotype in over 600 specific genetic syndromes are more commonly in association with isolated CP.(31) The proportion of CL/P associated with specific syndromes has been reported to be between $5 \%$ to $7 \%{ }^{(32)}$ The concordance rates for $\mathrm{CL} / \mathrm{P}$ is higher in monozygotic twin pairs.(33) there has been familial clustering and concordance in twins of CL/P and CP and are specific for each defect, and therefore the defects are considered to be etiologically heterogeneous. (34) There exists a male preponderance in CL/P along with predominance of cleft affecting the left side ${ }^{(35)}$. TGF $\alpha^{(36)}$ and MTHFR(37)genes have been amongst the most intensively studied variants over the years. However, the results are characterized by their inconsistency, reflecting the fact that further investigation of genedisease associations and related interactions is required to be done. (38)

An interesting recent finding is that the gene, IRF6, the gene implicated in Van der Woude syndrome has been shown to play a strong role in the isolated form of clefting, ${ }^{(39)}$ and a number of other independent studies in a range of different populations and ethnic groups have reported this finding. ${ }^{(40,41)}$ Other examples of gene variants involved in syndromic forms of CL/P with a Mendelian mode of inheritance producing phenocopies of non-syndromic CL/P include 
Kallmann syndrome (FGFR1), (42) ectrodactyly-ectodermal dysplasia/clefting (TP63), ${ }^{(43) X ~ l i n k e d ~}$ ankyloglossia/clefting (TBX22),(44) Gorlin Syndrome (PTCH), (45)and heterozygotes for the Margarita Island clefting syndrome (PVRL1), ${ }^{(46)}$ The implication is that these genes might harbour a mutation that could cause or modify the expression of isolated cleft lip and /or cleft palate.

GENE-ENVIRONMENT INTERACTION: In the light of the foregoing discussion, it seems plausible that common genetic polymorphisms are modifiers of the relationship between environmental and lifestyle factors and orofacial clefts. Hence, there may be population subgroups which have a particularly high or particularly low risk of clefts due to a combination of genetic susceptibility and exposure. Genetic polymorphisms involving the metabolism of alcohol, agents in tobacco and smoke as well as those involved in nutritional metabolism may be relevant to orofacial clefts. Hypotheses can be tested if appropriate information on these factors is collected retrospectively from the affected families. One of the main reasons for the difficulty in determining the aetiology of non-syndromic clefts is that it is polygenic multifactorial, with genetic predisposition to environmental factors being important aetiology.(47) Because of the potential public health benefits, numerous studies have been carried out to examine possible interactions. These include those between: TGF $\alpha$ (with smoking(48) and vitamin supplements), (49)TGFß3 (with smoking, alcohol), MSX1 (with smoking, alcohol),(50-51) polymorphisms influencing xenobiotic metabolism and smoking,(52-55) occupational exposures,(56) maternal medication usage,(54) retinoic acid receptor alpha (RARA) polymorphisms, maternal intake of vitamin $A,{ }^{(57)}$ polymorphisms influencing folate metabolism (MTHFR, RFC) and maternal folate intake.(50,58-60)

At a WHO consensus meeting in December 2004, a collaborative research pooling initiative was established through the WHO International Collaborative on Craniofacial Anomalies Project (http://www.who.int/genomics/anomalies/cfaproject/en/\#mtg) to undertake meta- and pooled analyses of studies. Collaborative efforts with different populations, ethnic groups, gene pools and environmental exposures across the world will assist in determining the multiple genes that modulate the effects of an exposure.(61) The principles of genetic Mendelian randomisation can be employed to aid in the identification and understanding of environmental factors in disease ${ }^{(62)}$

FUTURE OF CLEFT LIP AND PALATE IN INDIA: India, 1871 being one of the first documents to provide information on prevalence of a range of disabilities and diseases such as leprosy, blindness, deafness and insanity. ( One of the first documents to provide information on prevalence of disability and disease in India such as leprosy, blindness, deafness and insanity was documented in 1871). Since then India has made significant progress in combating infectious disease through improvements in sanitation, childhood nutrition, vaccination and other public health initiatives; and as a result, genetic disorders have assumed greater importance.

Based on the National Family and Health Survey, 1992-1993 (NFHS),(63) consanguinous marriages are uncommon in the Northern, Eastern and North Eastern states and its influence on diseases has not been quantified, with recessive genetic disorders being one example of an influence of consanguinity in the spectrum of human disease. There are very few studies and research about the influence of consanguinity on craniofacial anomalies or cleft lip and palate. 
In Southern India, consanguineous unions between biological kinds have a long tradition. (64) The highest rates are reported in the states of Andhra Pradesh, Karnataka and Tamil Nadu, with Kerala being an exception because of the strict avoidance of consanguineous marriage. In the pursuit of genetic research into cleft lip and palate and craniofacial anomalies, it would seem appropriate that an investigation/ research study is carried out on the influence of consanguinous marriage on non-syndromic cleft lip and palate.

Indian Doctors, Government health authorities along with the NGOs have expressed a keen desire to be involved with research studies of OFC and contribute towards multidisciplinary treatment approach as recommended by WHO. These included the establishment of high volume treatment centers, modern equipments, availability of specialist doctors of all departments, inter departmental co-ordination and sharing of inter-center research projects in relation to registration of OFC cases, treatment and the outcome of the treatment. The large volume of cleft cases in India is partly contributed, by the unmitigated debt of past generations wherein a proportion of the adult population with unrepaired clefts who were not treated for primary surgery and other rehabilitation care. To date, however, there has been little attempt by various health agencies to register and evaluate treatment outcome, carry out inter-centre comparisons of treatment protocols and to implement multi disciplinary treatment outcome as recommended by WHO.

CONCLUSION: Congenital facial defects are a pressing problem in India owing to the limited resources to treat such patients. Setting up an institute to treat children with cleft and craniofacial deformities in India presents problems with financing treatment for poor patients, procuring the right infrastructure, and employing well-trained human resources.

The logistics of setting up such a facility in a developing country like India and the future of funding for cleft treatment are important factors to consider while establishing a centre and upgrading of established health centre for patients with cleft and craniofacial anomalies. The aim of setting up such centres should be to provide quality comprehensive \& multidisciplinary treatment for patients belonging to sections of society with cleft and craniofacial anomalies.

In India large number of NGOs, government health agencies and health policies, and institutes are trying to address the problem of treatment and quality care of OFC cases. There is wide acceptance among various health agencies that an improvement in birth defects research, surveillance, and registration and quality treatment is required. Surveys and research on OFC by the various organization providing medical services for cleft lip and palate patients, availability of care, effects of previous surveys and importance of specific management techniques in bringing about improvement in the quality health care for OFC cases in our country is the need of time.

\section{REFERENCES:}

1. Cooper ME, Stone RA, et.al., Descriptive epidemiology of nonsyndromic cleft lip with or without cleft palate in Shanghai, China, from 1980 to 1989 . Cleft Palate Craniofac J. 2000; 37:274-80.

2. Murray JC. Gene environment causes of cleft lip and/or palate. Clin Genet. 2002; 61:248-56.

3. Global Strategies to Reduce the Health Care Burden of Craniofacial Anomalies. Report of WHO meetings on International Collaborative Research on Craniofacial Anomalies. Geneva, Switzerland, 2000 
4. Mossey P, Little J. Addressing the challenges of cleft lip and palate research in India. Indian J Plast Surg. 2009;42:9-18.

5. Orlagh H, Donald B, Peter H, Chris J. The psychosocial effects of cleft lip and palate - A systemic review. Eur J Orthod 2005;27:274-83.

6. Berbert, Campos C. Legal considerations in the management of cleft lip and palate. Cleft Palate Craniofac J 2007;44

7. 7.) Kumari S, Choudhary AK, Negi G, et.al., Prevalence of anemia among the general population of Bihar, India. Ind Med Gaz 2009;11 418-21.

8. 8).Trindade IE, Manco JC, TrindadeJr AS. Pulmonary function of individuals with congenital cleft palate. Cleft Palate Craniofac J 1992;29:429-34.

9. 9.) Greer, Foerster, Lukens, Rodgers. Wintrobe Clinical Haematology. Vol. 1, 2 nd ed. Philadelphia: Lipincott Williams and Wilkins; 2004. P. 325-9.

1(Vasan N. Management of children with clefts of the lip or palate: An overview. NZ Dent J 1999;95:14-20

11. Gopalakrishna A, Agrawal K. A status report on management of cleft lip and palate in India. Indian J PlastSurg 2010;43:66-75

12. JyotiDvivedi, Sanjay DvivediA clinical and demographic profile of the cleft lip and palate in Sub-Himalayan India: A hospital-based study Indian. J Plast Surg. 2012 :45/1: $115-120$

13. SrinivasGosla Reddy, Rajgopal R. Reddy, Incidence of cleft Lip and palate in the state of Andhra Pradesh, South India Indian J Plast Surg. 2010 Jul-Dec; 43(2): 184-189

14. UppalaRadhakrishna, et.at., Genomewide Scan for Nonsyndromic Cleft Lip and Palate in Multigenerational Indian Families Reveals Significant Evidence of Linkage at 13q33.1-34 , Am J Hum Genet. 2006 September; 79(3): 580-585.

15. Parul Jindal, GurjeetKhurana, et.al., Intra and postoperative outcome of adding clonidine to bupivacaine in infraorbital nerve block for young children undergoing cleft lip surgery. 2011 Jul-Sep; 5(3): 289-294.

16. Jyotsna Murthy, L. V. K. S. Bhaskar, Current concepts in genetics of nonsyndromic clefts ,Indian J Plast Surg. 2009 Jan-Jun; 42(1): 68-81.

17. Brett T Chiquet, Syed S Hashmi, et.al., Genomic screening identifies novel linkages and provides further evidence for a role of MYH9 in nonsyndromic cleft lip and palateEur J Hum Genet. 2009 February; 17(2): 195-204. Published online 2008 August 20.

18. Soraya Beiraghi,et.al., Autosomal Dominant Nonsyndromic Cleft Lip and Palate: Significant Evidence of Linkage at 18q21.1. Am J Hum Genet. 2007 July; 81(1): 180188.

19. Kallen K. Maternal smoking and orofacial clefts. Cleft Palate-Craniofac J. 1997;34:116.

20. Munger RG, Romitti PA, et. al., Maternal alcohol use and risk of orofacial cleft birth defects. Teratology. 1996;54:27-33.

21. Holmberg PC, Hernberg S, Kurppa K, Rantala K, Riala R. Orofacial clefts and organic solvent exposure during pregnancy. Int Arch Occup Environ Health. 1982;50:371-6.

22. Nurminen T, Rantala K, Kurppa K, Holmberg PC. Agricultural work during pregnancy and selected structural malformations in Finland. Epidemiology. 1995;6:23-30.

23. Wyszynski DF, Beaty TH. Review of the role of potential teratogens in the origin of human non syndromic oral clefts. Teratology. 1996;53:309-17.

24. Curtis EJ, Fraser FC, Warburton D. Congenital cleft lip and palate. Am J Dis Child. 1961; 
102:853.

25. Khoury MJ, Stewart W, Beaty TH. The effect of genetic susceptibility on causal inference in epidemiologic studies. Am J Epidemiol. 1987;126:561-7.

26. Stanier P, Moore GE (2004) Genetics of cleft lip and palate: syndromic genes contribute to the incidence of non-syndromic clefts. Hum Mol Genet 13:R73-R81.

27. Ankola AV, Nagesh L, Hedge P, Karibasappa GN (2005) Primary dentition status and treatment needs of children with cleft lip and/or palate. J Indian SocPedodPrev Dent 23:80-82.

28. Slaney SF, Oldridge M, et al (1996) Differential effects of FGFR2 mutations on syndactyly and cleft palate in Apert syndrome. Am J Hum Genet 58:923-932.

29. Paavola P, Salonen R, Weissenbach J, Peltonen L (1995) The locus for Meckel syndrome with multiple congenital anomalies maps to chromosome 17q21-q24. Nat Genet 11:213-215.

30. Dixon MJ, et.al.,(1993) Narrowing the position of the Treacher Collins syndrome locus to a small interval between three new microsatellite markers at 5q32-33.1. Am J Hum Genet 52:907-914.

31. Wong FK, Hagg U. An update on the aetiology of orofacial clefts. Hong Kong Med J. 2004;10:331-6.Review.

32. Tolarova MM, Cervenka J. Classification and birth prevalence of orofacial clefts. Am J Med Genet.1998;75:126-37.

33. Little J, Bryan E. Congenital anomalies in twins. SeminPerinatolol. 1986;10:50-64.

34. Sivertsen A, Wilcox AJ, et al. Familial risk of oral clefts by morphological type and severity: Population based cohort study of first degree relatives. BMJ.2008;336:4324.

35. Mossey PA, Little J. Epidemiology of oral clefts: An international perspective. In: Wyszynski DF, editor. Cleft lip and palate: From origins to treatment. New York: Oxford University Press; 2002. pp. 127-58.

36. Zeiger JS, Beaty TH, Liang KY. Oral clefts, maternal smoking, and TGFA: A metaanalysis of gene environment interaction. Cleft Palate Craniofac J. 2005;42:58-63.

37. Verkleij-Hagoort A, Bliek Jet.al., Hyperhomocysteinemia and MTHFR polymorphisms in association with orofacial clefts and congenital heart defects: A meta-analysis. Am J Med Genet A. 2007; 143:952-60.

38. Ioannidis JP, et al. A network of investigator networks in human genome epidemiology. Am J Epidemiol. 2005;162: 302-4.

39. Zucchero TM, Cooper ME, et al. Interferon regulatory factor 6 (IRF6) is a modifier for isolated cleft lip and palate. N Engl J Med. 2004; 351:769-80.

40. Ghassibe $M$, Bayet $B$, et al. Interferon regulatory factor-6: A gene predisposing to isolated cleft lip with or without cleft palate in the Belgian population. Eur J Hum Genet. 2005;13: 1239-42.

41. Scapoli L, PalmieriA,et al. Strong evidence of linkage disequilibrium between polymorphisms at the IRF6 locus and nonsyndromic cleft lip with or without cleft palate, in an Italian population. Am J Hum Genet. 2005; 76:180-3.

42. Jugessur A, Rahimov F, et al. Genetic variants in IRF6 and the risk of facial clefts: Single-marker and haplotype-based analyses in a population-based case-control study of facial clefts in Norway. Genet Epidemiol. 2008; 32:413-24.

43. Dode C, Levilliers J, et al. Loss of function mutations in FGFR1 cause autosomal 
dominant Kallmann syndrome. Nat Genet. 2003;33:463-5.

44. Barrow LL, van Bokhoven $H$, et al. Analysis of the p63 gene in classical EEC syndrome, related syndromes, and non-syndromicorofacial clefts. J Med Genet. 2002;39:559-66.

45. Braybrook $\mathrm{C}$, et al. The T-box transcription factor gene TBX22 is mutated in X-linked cleft palate and anykloglossia. Nat Genet.2001;29:179-83.

46. Kimonis VE, et al. Clinical manifestations in 105 persons with nevoid basal cell carcinoma syndrome. Am J Med Genet.1997;69:299-308.

47. Sozen MA, Suzuki K, et.al., Mutation of PVRL1 is associated with sporadic, nonsyndromic cleft lip/palate in northern Venezuela. Nat Genet.2001;29:141-2.

48. Jakobsen LP, et al. The genetic basis of the Pierre Robin sequence. Cleft Palate Craniofac J. 2006;43:155-9.

49. Shaw GM, et al. Orofacial clefts, parental cigarette smoking, and transforming growth factor-alpha gene variants. Am J Hum Genet.1996; 58:551-61.

50. Shaw GM, Wasserman CR, Murray JC, Lammer EJ. Infant TGF-alpha genotype, orofacial clefts, and maternal periconceptional multivitamin use. Cleft Palate Craniofac J. 1998; 35:366-70.

51. Romitti PA, Lidral AC, et.al., Candidate genes for nonsyndromic cleft lip and palate and maternal cigarette smoking and alcohol consumption: Evaluation of genotypeenvironment interactions from a population-based case-control study of orofacialclefts.Teratology. 1999;59:39-50.

52. Maestri NE, Beaty TH, et al. Application of transmission disequilibrium tests to nonsyndromic oral clefts: Including candidate genes and environmental exposures in the models. Am J Med Genet. 1997;73:337-44.

53. Hartsfield JK, et.al., Analysis of the EPHX1 113 polymorphism and GSTM1 homozygous null polymorphism and oral clefting associated with maternal smoking. Am J Med Genet. 2001;102:21-4.

54. van Rooij IA, et al. Smoking, genetic polymorphisms in biotransformation enzymes, and nonsyndromic oral clefting: A gene-environment interaction. Epidemiology. 2001;12:502-7.

55. van Rooij IA, Groenen PM, et.al., Orofacial clefts and spina bifida: N-acetyltransferase phenotype, maternal smoking, and medication use.Teratology. 2002;66:260-6.

56. Lammer EJ, Shaw GM, Iovannisci DM, Finnell RH. Periconceptional multivitamin intake during early pregnancy, genetic variation of acetyl-N-transferase 1 (NAT1), and risk for orofacial clefts. Birth Defects Res A ClinMolTeratol. 2004;70:846-52.

57. 57). Shaw GM, Nelson V,et al.,. Maternal occupational chemical exposures and biotransformation genotypes as risk factors for selected congenital anomalies. Am J Epidemiol. 2003;157:475-84.

58. Mitchell LE, Murray JC, O'Brien S, Christensen K. Retinoic acid receptor alpha gene variants, multivitamin use, and liver intake as risk factors for oral clefts: A populationbased case-control study in Denmark, 1991-1994. Am J Epidemiol. 2003;158:69-76.

59. van Rooij IA, Vermeij-Keers C, et al. Does the interaction between maternal folate intake and the methylenetetrahydrofolatereductase polymorphisms affect the risk of cleft lip with or without cleft palate? Am J Epidemiol. 2003;157:583-91.

60. Little J, Gilmour M,et al. Folate and clefts of the lip and palate: A UK based case-control study: Part I: Dietary and supplemental folate. Cleft Palate Craniofacial J. 2008;45:42027. 
61. Chevrier C, et al. Fetal and maternal MTHFR C677T genotype, maternal folate intake and the risk of nonsyndromic oral clefts. Am J Med Genet A.2007;143:248-57.

62. Fryer AA, Jones PW. Interactions between detoxifying enzyme polymorphisms and susceptibility to cancer. IARC Sci Publ. 1999;148:303-22.

63. Davey Smith G, Ebrahim S. What can Mendellian Randomisation tell us about Modifiable, Behavioural and Environmental Exposures? BMJ. 2005;330:1076-9.

64. IIIPS National Family and Health Survey, India, 1992-93. Mumbai: International Institute for Population Sciences; 1995.

65. Sastri KA. A history of South India: From prehistoric times to the fall of Vijayanagar. 4th ed. Madras: Oxford University Press; 1976. 